\title{
The Effect of Rapid Solidification on Microstructure and Corrosion of Advanced Biomaterial Co-Cr-Mo-C Alloy
}

\author{
Hamid-Reza Erfanian-NazifToosi, Hugo F. Lopez \\ Department of Materials Science and Engineering, University of Wisconsin-Milwaukee, Milwaukee, USA \\ E-mail:erfania2@uwm.edu
}

Received: 20 September 2019; Accepted: 11 October 2019; Available online: 30 December 2019

\begin{abstract}
In this research, the microstructure and corrosion properties of rapidly solidified Co-Cr-Mo-C alloy as an advanced biomaterial alloy were studied. The use of rapid solidification casting method represents significant changes in not only the amount of formed $\varepsilon$-HCP phase, which is strongly influenced by rapid solidification, but also in electrochemical behavior and solidified structure. In this research, rapid solidified Co-Cr-Mo-C alloy is studied using OM, SEM, EDS, XRD, and dynamic potentiostate. Co-alloy ingots were melted into an induction furnace filled by argon gas and casted into a V-shape sand and chill copper molds to prepare rapid solidified samples and its properties were measured in different cooling rates. The microstructure examination demonstrating the structure of alloy is mainly consist of columnar dendritic structure with the distribution of carbides within primary and secondary dendrites arms and finer dendritic structure along with modified carbide distribution will be achieved by rapid solidification. This structure will improve alloy's corrosion behavior and reduces its corrosion rate when it is tested in Ringer's solution as an electrolyte.
\end{abstract}

Keywords: Biomaterial; Co-Cr alloy; Rapid solidification; Hip and Knee implant; Corrosion.

\section{Introduction}

Co-based alloys are increasingly being used in biomedical application for their biocompatibility, excellent corrosion resistance, and mechanical and wear properties [1, 2]. Solidified microstructures of as-cast cobalt alloys is mainly FCC dendritic structure in presence of segregation, and second phase precipitates within the matrix and along the interdendritic regions [3]. Since the introduction of Co-based alloys as prosthesis material, a considerable amount of research has been done on examining the possibility of enhancing mechanical properties and biocompatibility of this alloy by modifying the microstructure [1, 3-6].Overall, Co-Cr-Mo-C alloys made by investment casting are showing poor ductility, high shrinkage porosity, interdendritic segregation, and intermetallic compounds brittleness. Thus, to improve alloy performance for high lifetime service in biomedical applications, modifications in alloy design and casting technology have taken place [7]. Minimizing the formation of brittle intermetallic compounds along the interdendritic regions during solidification have been considered as part alloy design solutions [8].

In pure Co, the $\gamma \leftrightarrow \varepsilon$ FCC to HCP allotropic transformation takes place at a $\mathrm{T}_{\mathrm{C}}=417^{\circ} \mathrm{C}$ ( $690 \mathrm{~K}$ ) by a displacive martensitic transformation [9]. The transformation temperature, is even shifted toward higher temperatures (near $\left.970^{\circ} \mathrm{C}[10]\right)$ in Co-27Cr-5Mo-0.05C wrought alloys as $\mathrm{Cr}$ and Mo expand the HCP field of stability. The resultant HCP phase from the martensitic transformation is known as $\varepsilon$-martensite [9]. According to phase diagram of Co$\mathrm{Cr}$; in solidified alloy at room temperature $\varepsilon$-HCP phase and at temperatures higher than $800^{\circ} \mathrm{C} \gamma$-FCC phase are expected to be thermodynamically stable. However, the $\gamma \leftrightarrow \varepsilon$ is strongly restricted by nucleation phenomena and will lead to formation of retained $\gamma$-FCC phase in most conventionally solidified Co-Cr-Mo-C alloys at room temperature as well as higher temperature [11,12] because the $\gamma \leftrightarrow \varepsilon$, FCC to HCP, transformation is rather slow under normal cooling conditions [13, 14]. In Co alloys, the martensitic transformation can be achieved by (1) isothermal, (2) athermal, and (3) strain induced mechanism.

In athermal transformations the amount of transformed martensite depends primarily on the quenching temperature and not on the residence time at this temperature. Experimentally, it has been found that in conventionally solidified Co-Cr-Mo-C alloys the reported amounts of athermal $\varepsilon$-martensite are not more than 20 vol. \% in most cases [15]. The limited extent of athermal martensite induced in Co-Cr-Mo alloys has been attributed to the lack of enough defects necessary for the spontaneous formation of $\varepsilon$-embryos during alloy cooling from the $\gamma$-phase [16].

Athermal reaction is controlled by distribution of faulting defects which act as effective nucleation sites for $\varepsilon$ - 
martensite embryos. These faulting defects including tilt boundaries, twin intersections, incoherent twin boundaries or incoherent inclusion interfaces expedite the formation of $\varepsilon$-martensite embryos by having a longrange stress field [6]. Olson et al. [17] have shown that the spontaneous formation of $\varepsilon$-martensite embryos can be achieved when the alloy stacking fault energy becomes zero or negative. The nucleation defect being a faulting mechanism consisting of a group of lattice dislocations where the motion of a Shockley partial on every second FCC closed packed plane gives rise to an $\varepsilon$-phase nucleus. Yet, the estimated density of the proper faulting defects is of the order of $10^{5}-10^{7} / \mathrm{cm}^{3}$, which explains the sparse amounts of precipitated athermal martensite in cobalt based alloys [17].

Many studies have shown that the metal ions dissolved from prostheses in body because of the corrosion and wear debris in biological environment cause an allergy and implant failure $[13,18]$. Investigations on the corrosion characteristics of Co-Cr-Mo-C alloy in different body solutions using potentiodynamic method have been done and shown high corrosion resistivity and small passivity region for this alloy in joint fluid and body fluid simulated environments [1, 5, 7, 19-21]. S. Hiromoto et al. [1] considered the effect of forging ratio on corrosion behavior of Co-Cr-Mo alloys in different environment, they found that alloy with low forging ratio shows lower passive current density and also increasing the grain boundaries by forging will decrease the corrosion resistant of alloy. F. Ren et al. [20] investigated the effect of physiological simulated solution on corrosion behavior of ultra-fine grain Co-28Cr-6Mo made by mechanical alloying process. Results demonstrate positive shift in corrosion potential and lower corrosion density as compared to conventional Co-Cr-Mo cast alloys. The study on influence of precipitate carbides on corrosion behavior of a biomedical Co-Cr-Mo-C alloy shows at high anodic potential (0.5-0.7 $\mathrm{V}_{\text {sat }} \mathrm{Ag} / \mathrm{AgCl}$ ) metal dissolution occurs at the carbide boundaries and, in the form of etching-like dissolution, on the carbides.

Despite the tremendous volume of research that has been done on the properties and modifications of $\mathrm{Co}-\mathrm{Cr}$ and $\mathrm{Co}-\mathrm{Cr}-\mathrm{Mo}-\mathrm{C}$ alloy over the past several decades, there is no published article on the effect of solidification rate and rapid solidification on the mechanical, physical, and electrochemical properties of Co-Cr-Mo-C alloy. In this investigation, samples were prepared by rapid solidification. Microstructure characteristics of as-cast and rapidly solidified implant alloy were studied. Potentiodynamic method is used to investigate the corrosion behavior of samples in biological Ringer's solution. Experimental results from both microstructure and electrochemical analysis were compared and discussed.

\section{Materials and methods}

Cobalt alloy parts containing 28 wt. \% Cr, 6 wt. \% Mo, and 0.3 wt. \% C in conform to ASTM F-75 were melted in an alumina crucible using a vacuum induction furnace. The system was evacuated three times with high purity argon prior to vacuum melting. When the parts turned into liquid at $2273 \mathrm{~K}$ (approx. $2000{ }^{\circ} \mathrm{C}$ ); the chamber was immediately evacuated, and the melt was degassed. On the other hand, the temperature was dropped to $1873 \mathrm{~K}$ (approx. $1600{ }^{\circ} \mathrm{C}$ ) and a slag was collected from the top of the melt. Finally, the molten alloy was cast into a wedge-shaped sand and copper mold. The copper wedge mold sides were covered by an alumina sheet to keep the heat flow predominantly in one direction, (Figure 1). Table 1 shows the chemical composition of cast alloy. Before casting, Pt/Pt-18\% Rh thermocouples were centrally inserted into the wedge copper mold at 20, 60, and $90 \mathrm{~mm}$ from the tip to the top of the mold cavity, at half thickness locations of 1.0, 3.0, and $4.5 \mathrm{~mm}$, respectively (Figure 1). The as-cast ingots were then sectioned along the lateral direction in the plane normal to the tip of the wedge and polished followed by electrolyte etching using a $60 \mathrm{vol}$. \% $\mathrm{HNO} 3+40 \mathrm{vol}$. $\% \mathrm{H}_{2} \mathrm{O}$ solution at $6 \mathrm{~V}$ and $5 \mathrm{~mA}$ for 20 s. Preparedsamples were studied by means of optical microscopy and scanning electron microscopy (SEM). SEM and EDX analysis of specimens were performed using a Topcon SM300 Scanning Electron Microscope at 20KV of intensity.

The samples of as-cast alloy and rapidly solidified alloy from different locations of "V" shaped mold were finished by $1200 \mathrm{SiC}$ abrasive paper and polished by $\mathrm{Al}_{2} \mathrm{O}_{3} 1 \mu \mathrm{m}$ solution for corrosion tests. Biological Ringer's solution consists of $9 \mathrm{~g} \mathrm{NaCl}, 0.43 \mathrm{~g} \mathrm{KCl}, 0.24 \mathrm{~g} \mathrm{CaCl}_{2}$, and $0.2 \mathrm{~g} \mathrm{NaHCO}_{3}$ in 1 liter of distilled water was used as an electrolyte. Super saturated $\mathrm{Ag} / \mathrm{AgCl}$ and Pt plate were used as reference electrode and counter, respectively. The sample was fixed in an electron holder with O-ring [22]. To stabilize the potential, samples immersed in the solution for about $15 \mathrm{~min}$. The stabilized potential was used as the open-circuit potential ( $\mathrm{E}_{\text {ocp}}$ ) of samples. Samples were polarized in a range of $-0.3 \mathrm{~V}$ to $+1.3 \mathrm{~V}$ versus $E_{\text {corr }}$ with the scanning rate of $10 \mathrm{mV} \mathrm{min}^{-1}$. In order to measure the corrosion rate, a potentiostat Biologic SP-200 and EC-Lab v10.33 as the corrosion software were used for electrochemical control and data analysis, respectively. The test was repeated three times for each sample to have reliable results. The corrosion current density $\left(i_{\text {corr }}\right)$ and other corrosion parameters including anodic and cathodic Tafel slopes $\left(\mathrm{b}_{\mathrm{a}}\right.$ and $\left.-\mathrm{b}_{\mathrm{c}}\right)$, were measured by considering the polarization curves by Tafel extrapolation. 


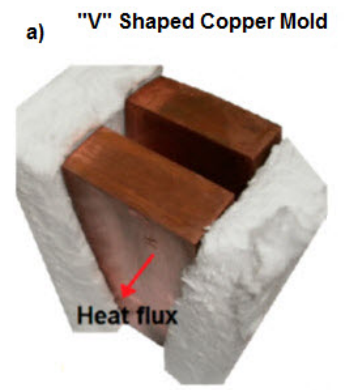

"V" Shaped Ingot

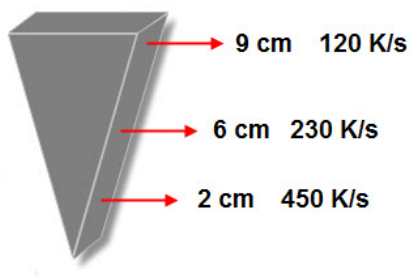

Figure 1. (a)Wedge-shaped copper mold isolated in both sides by an alumina sheet; (b) "V" shaped ingot showing three different cooling rate zones: $90 \mathrm{~mm}$ high: $120 \mathrm{~K} / \mathrm{s}, 60 \mathrm{~mm}$ high: $230 \mathrm{~K} / \mathrm{s}$, and $20 \mathrm{~mm}$ high: $450 \mathrm{~K} / \mathrm{s}$.

Table 1. Chemical composition (wt\%) of as-cast Co-Cr-Mo-C sample

\begin{tabular}{llllllllllll}
\hline Element & $\mathrm{C}$ & $\mathrm{S}$ & $\mathrm{Mn}$ & $\mathrm{Si}$ & $\mathrm{P}$ & $\mathrm{Cr}$ & $\mathrm{Ni}$ & $\mathrm{Mo}$ & $\mathrm{W}$ & $\mathrm{Fe}$ & $\mathrm{Co}$ \\
\hline Cast sample & 0.3 & 0.003 & 0.21 & 0.61 & 0.0014 & 28.0 & 0.43 & 5.82 & 0.02 & 0.38 & $\mathrm{Bal}$ \\
\hline
\end{tabular}

\section{Results and discussion}

The microstructure of the as-cast Co-Cr-Mo-C alloy consists of cobalt-rich matrix with dendritic structure and a relatively large volume fraction of interdendritic precipitates. During the solidifying stage, some amount of the metastable phase will retain at the room temperature when $\mathrm{Co}-\mathrm{Cr}-\mathrm{Mo}-\mathrm{C}$ alloy solidified through the FCC phase field. The resultant will be cobalt-rich matrix phase consists of residual phase and phase coupled with intragranular striations. The interdendritic precipitate was identified as carbide that also exists continuously at the grain boundaries. This brittle phase corresponding to the higher solute content ( $\mathrm{Cr}, \mathrm{Mo})$ at grain boundaries causes a stress concentration and leading to the early fracture. The intragranular striations are related to $\varepsilon$-martensite phase formed because of stacking faults. $\mathrm{Cr}$ and Mo solutes can diffuse preferentially at the stacking faults with increasing temperature [23, 24].

The maximum cooling rate with this experimental measured at: $450 \mathrm{~K} / \mathrm{s}$ at a distance $20 \mathrm{~mm}$ from the tip of the "V" shape ingot; $300 \mathrm{~K} / \mathrm{s}$ at $60 \mathrm{~mm}$ at the center of the ingot; $120 \mathrm{~K} / \mathrm{s}$ at $90 \mathrm{~mm}$ at the top of the ingot; and conventional cooling rate from sand cast sample approximately $10 \mathrm{~K} / \mathrm{s}$. Figure 2 and 3 show the various microstructures regarding the cooling rate found in the studied locations (at $20 \mathrm{~mm}, 60 \mathrm{~mm}$ and $90 \mathrm{~mm}$ from bottom to top in the rapid solidified wedge ingot and top of the sand mold). It can be clearly observed that the dominant microstructure is the columnar dendrites.

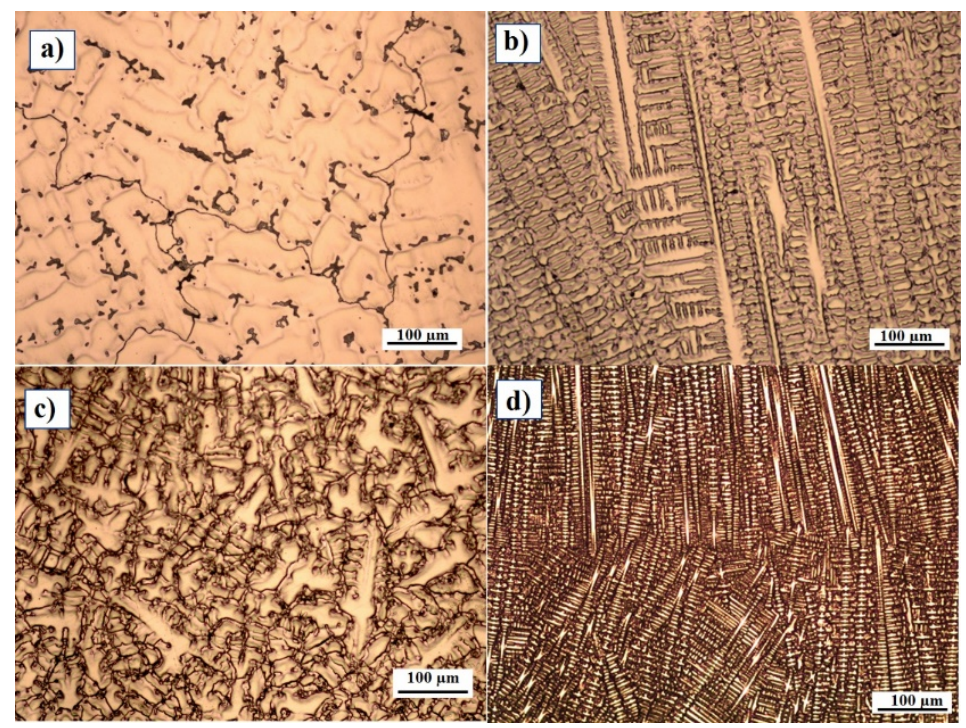

Figure 2. Optical images of Co-Cr-Mo-C alloy regarding its distance from the tip of the "V" shape mold at 100xa) Sand mold cast-90 mm, b) Cu mold cast-90 mm, c) Cu mold cast-60 mm, and d) Cu mold cast-20 mm

Microstructure analysis of Co alloy revealed the presence of blocky and lamellar (dendritic) shape carbides in this alloy (Figure 4), depending on its cooling rate. Physical and chemical factors have a great influence on the carbide formation: the main alloying elements are responsible for their composition and structure, and the cooling 
rate largely affects their size and shapes. According to Tylor and Waterhouse [25] these carbides are most likely to be $\mathrm{M}_{23} \mathrm{C}_{6}$ and $\mathrm{M}_{6} \mathrm{C}$. Cr has a predominant role in the formation of the carbide type $\mathrm{M}_{23} \mathrm{C}_{6}$ (where $\mathrm{M}=\mathrm{Co}, \mathrm{Cr}$, $\mathrm{Mo}$ ), but also Mo, when present in large quantities, can promote carbide precipitation in the form of $\mathrm{M}_{6} \mathrm{C}$. Figure 4 shows two types of carbides, with their corresponding EDS analysis, formed in Co-Cr-Mo-C alloy due to its cooling rate. It is found that in low cooling rate solidification, carbides are larger and dendritic shape while in high cooling rate solidification; carbides are blocky shape and finer in compare with those in low cooling rate. It can be understood from the EDS results that in low cooling rate the major alloying element in carbides is Mo (Figure 4c), while $\mathrm{Cr}$ is the predominant alloying element in high cooling rate Co alloy and represent blocky shape carbides along with Mo (Figure 4d).

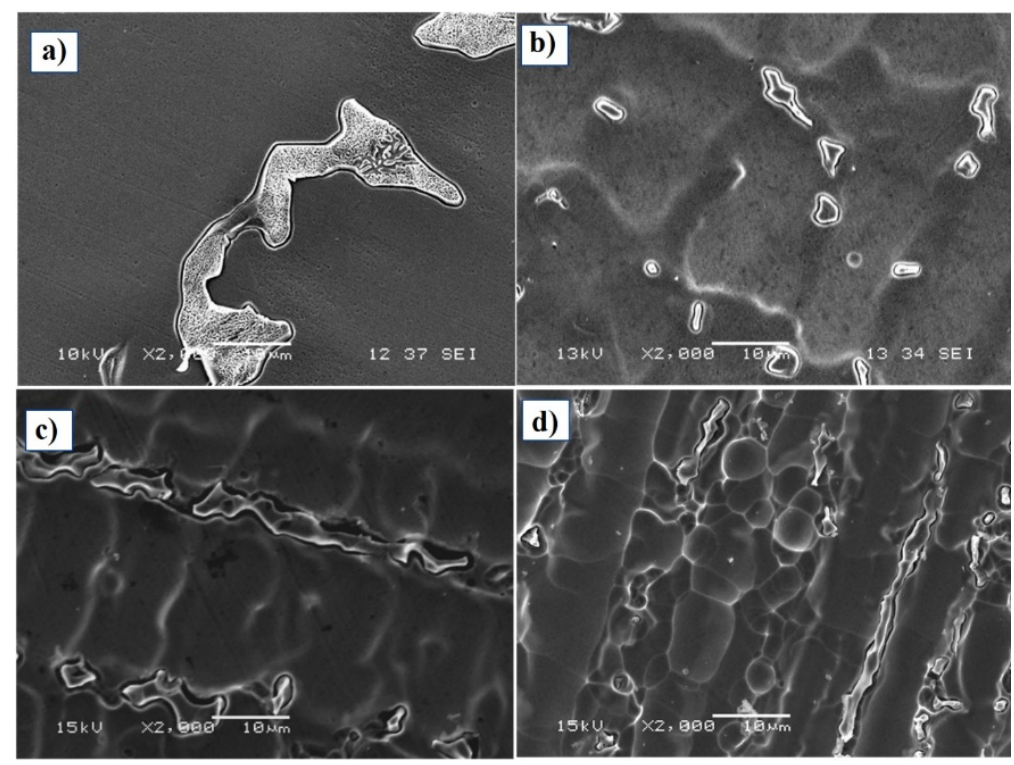

Figure 3. SEM images of Co-Cr-Mo-C alloy regarding its distance from the tip of the "V" shape mold at 2000xa) Sand mold cast-90 mm, b) Cu mold cast-90 mm, c) Cu mold cast-60 mm, and d)Cu mold cast-20 mm
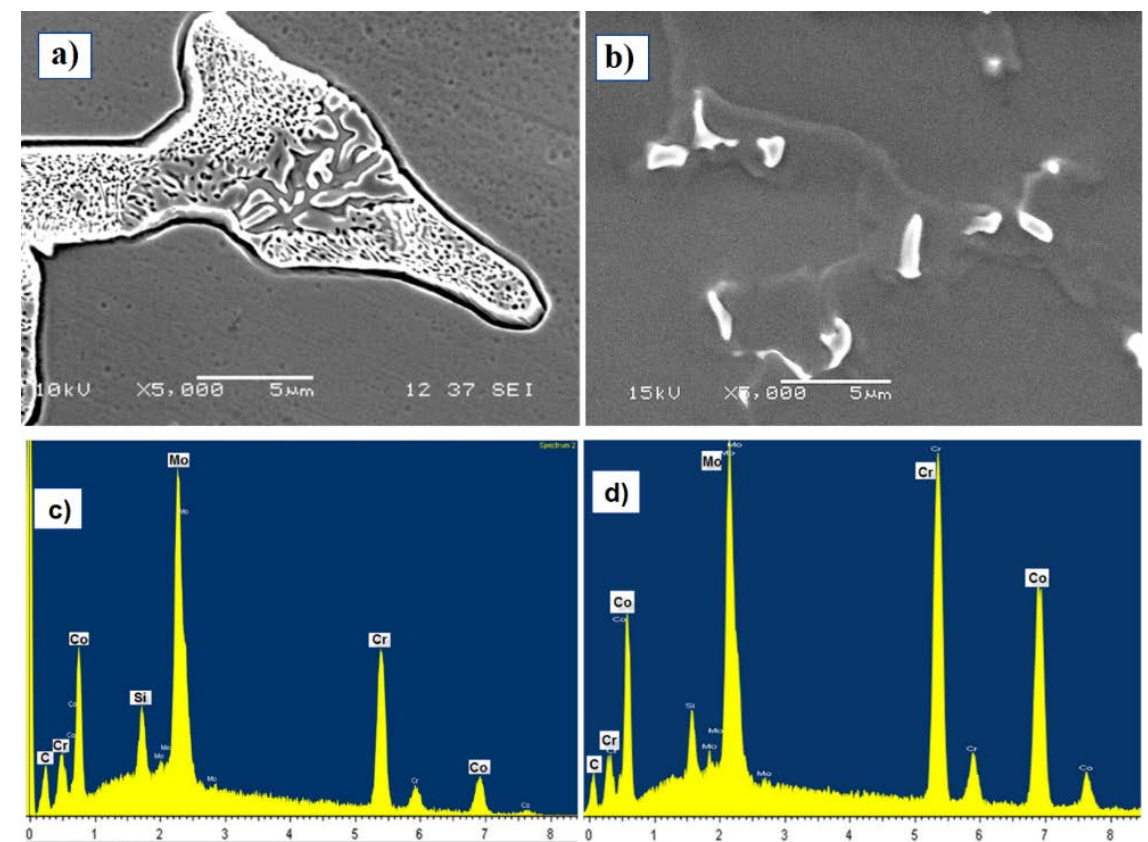

Figure 4. Showing carbide morphology in Co-Cr-Mo-C alloy regarding its cooling rate, a) $10 \mathrm{~K} / \mathrm{s}$ cast in sand mold $90 \mathrm{~mm}$ from the tip of "V" shaped mold, and b) $450 \mathrm{~K} / \mathrm{s}$ cast in copper mold $20 \mathrm{~mm}$ from the tip of "V" shaped mold

Samples were analyzed using X-ray diffraction to measure the quantity of developed $\gamma$-FCC and $\varepsilon$-HCP phases. On all samples, XRD peaks originated from $\gamma$-FCC and $\varepsilon$-HCP phases were observed. Sage and Guillaud [26] proposed the quantitative model to calculate the developed HCP phase in the Co-alloy. According to their model, 
only the diffraction patterns corresponding to $(002)_{\mathrm{FCC}}$ and $(10 \overline{1} 1)_{\mathrm{HCP}}$ should be considered because they are the only well distinguished and not overlapped diffraction patterns at a given $2 \theta$. The intensities of (002) FCC peak at $50.5^{\circ}$ and $(10 \overline{1} 1)_{\mathrm{HCP}}$ at $46.5^{\circ}$ are used to calculate the weight percentage of $\gamma$-FCC and $\varepsilon$-HCP, respectively. The following equation [26] is used to calculate the FCC and HCP relative amounts quantitatively in Co-Cr-Mo-C alloy.

$$
\frac{1-x}{x}=1.5 \frac{I_{(002) \mathrm{FCC}}}{I_{(10 \overline{1} 1) \mathrm{HCP}}} \times 100
$$

Where $x$ is HCP weight percentage, $I_{(002) \mathrm{FCC}}$ and $I_{(10 \overline{1}) \mathrm{HCP}}$ are integrated areas of the intensity peak correspond to $\gamma$-FCC and $\varepsilon$-HCP phases, respectively. Quantitative measurements of $\varepsilon$-HCP developed phase by using Eq. 1 determines the formation of approximately $46 \% \varepsilon$-martensite (HCP) phase in the sample with the highest cooling rate and less than $1 \%$ in the sample with the lowest cooling rate, Figure 5 . Intrinsic stacking faults are known to be the potential sites for $\varepsilon$-HCP phase nucleation as a result of lattice dislocations dissociate into Shockley partials. Because of relatively small stacking fault energy of Co-alloy, this transformation happens in Co-alloy spontaneously $[6,27]$. This will show that rapid solidification is an effective method to increase the density of faulting defects and consequently prompt transformation of $\gamma \rightarrow \varepsilon$. Although, the best wear properties in Co-based alloys are found when the alloy matrix is fully HCP, either in metal on metal wear couples, or in metal on UHDPE wear couples [28, 29], the fatigue properties are significantly reduced when the matrix is fully HCP [15]. Apparently, the limited number of slip systems in the HCP matrix severely limits plastic deformation, thus promoting fatigue cracking. Moreover, the mechanical properties (strength and ductility) of Co-based alloys are strongly influenced particularly by the amount of carbon, nitrogen, grain size and by the processing method (casting versus brought or powder processing). Nevertheless, it is worth mentioning that modifications to these properties, particularly ductility have been found through additions of nitrogen and grain size control [30, 31]. Thus, It is very important to note the dendrite arm spacing (DAS) and secondary dendrite arm spacing (SDAS) for evaluating microstructure of this alloy. In this research work, SDAS lower than $5 \mu \mathrm{m}$ were obtained in the bulk microstructure of samples located on $20 \mathrm{~mm}$ from copper mold. In addition, precipitates are randomly distributed in the primary and secondary arms of the matrix, which were identified with scanning electron microscopy. As it is shown in figure 2, increasing the cooling rate will decrease the DAS, SDAS, and carbide size which have improvement effects on alloy strength and its hardness.

Figure 6 shows the anodic and cathodic polarization curves for Co-Cr-Mo-C alloy in rapidly solidified and sand cast conditions in Ringer's solution. Corrosion parameters such as $\mathrm{E}_{\text {corr }}, \mathrm{i}_{\mathrm{corr}}, \mathrm{b}_{\mathrm{a}}$ and $\mathrm{b}_{\mathrm{c}}$ are measured and reported in Table 2. According to the results, increasing the cooling rate will improve the electrochemical behavior of alloy. The samples with higher cooling rate show higher corrosion potential and lower corrosion rate. The results show that the sand cast sample has the lowest $\mathrm{E}_{\text {corr }}$ and higher $\mathrm{i}_{\text {corr }}$ than the copper mold which was cast at $20 \mathrm{~mm}$ from the tip of the mold sample. The cathodic current densities show a rather linear region with negative slope and then the slope increases to zero. No significant differences are detected in the cathodic current densities depending on the samples.

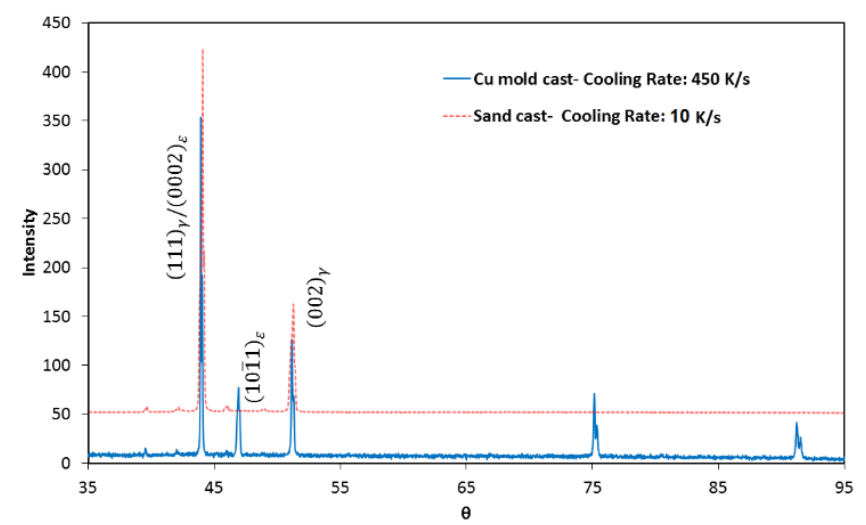

Figure 5. XRD results of Co-Cr-Mo-C alloy a) Cu mold cast- 2cm from tip (cooling Rate: $450 \mathrm{~K} / \mathrm{s}$ ) and b) Sand cast- $9 \mathrm{~cm}$ from tip (Cooling Rate: $10 \mathrm{~K} / \mathrm{s}$ ).

Solidified structure, size and distribution of carbides and the amount of $\varepsilon$-HCP phase characterize each sample. This means that different microstructural properties affect the corrosion behavior of samples. Better corrosion resistivity obtained by highest cooling rate, rapid solidification, is believed to be the result of better distribution of 
alloying elements, carbides, and lack of grain boundaries. Figure 2 shows the optical image of samples microstructure solidified at different cooling rate. As it shown in Figure 2, increasing cooling rate will highly reduce the density of grain boundaries. It is well known that the excellent corrosion characteristics in Co-Cr alloys are due to the passive layer formed on its surface $[1,7,32]$ which prevents these materials from suffering greater damage even in biological environments. On the other hand, the protectiveness of passive oxide layer in sand cast sample is higher than those with 120 and $230 \mathrm{~K} / \mathrm{s}$ cooling rate according to its wider passivity region. The reason of narrower passivity region of mentioned samples can be because of carbides size and distribution. The dispersion of carbides causes the increase in local active cell between carbides and base alloy, and then the increase in local corrosion is the result which will lead to pitting corrosion and consequently damaging the passive layer[1]. Local corrosion during passivity causes failure in oxide film and as a result, smaller passivity region. The increase in grain boundaries volume fraction and the precipitates in grain boundaries cause the decrease in protectiveness of the passive oxide film [1].

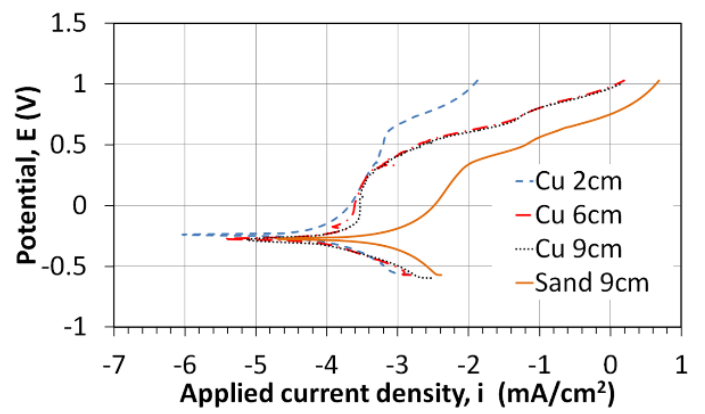

Figure 6. Potentiodynamic curves for Co-Cr-Mo-C alloy in different conditions (Cu: Cu mold cast, Sand: Sand mold cast).

Table 2. Corrosion parameters for Co-Cr-Mo-C alloys in Ringer's solution

\begin{tabular}{lllll}
\hline Mold/Distance from Tip/Cooling Rate & $\mathbf{b}_{\mathbf{a}}(\mathbf{m V})$ & $-\mathbf{b}_{\mathbf{c}}(\mathbf{m V})$ & $\mathbf{i}_{\text {corr }} \mathbf{( A / \mathbf { c m } ^ { 2 } )}$ & $\mathbf{E}_{\text {corr }}(\mathbf{m V})$ \\
\hline $\mathrm{Cu} / 20 \mathrm{~mm} / 450 \mathrm{Ks}^{-1}$ & 135 & 141 & 0.02 & -240 \\
$\mathrm{Cu} / 60 \mathrm{~mm} / 230 \mathrm{Ks}^{-1}$ & 171 & 170 & 0.07 & -270 \\
$\mathrm{Cu} / 90 \mathrm{~mm} / 120 \mathrm{Ks}^{-1}$ & 185 & 191 & 0.06 & -278 \\
$\mathrm{Sand} / 90 \mathrm{~mm} / 10 \mathrm{Ks}^{-1}$ & 175 & 171 & 0.09 & -280 \\
\hline
\end{tabular}

\section{Conclusions}

In this research, an alternative solidification process is proposed which could be used to manufacture Co-CrMo-C alloys with unique microstructures.

1) Dendrite refinement and either elimination or reduction of interdendritic segregation in cast alloys was observed, which can be considered as one of the microstructural achievements due to rapid solidification. The morphology and size of the carbides were highly affected by cooling rate.

2) Rapid solidification effects, such as excess vacancies and the development of numerous stacking faults and corresponding intersections, strongly favored the athermal martensite. The athermal martensite microstructure was confirmed by means of XRD. Results show the increase of formed $\varepsilon$-HCP phase to $46 \%$ by rapid solidification.

3) Potentiodynamic polarization curves indicated that corrosion resistance of Co-Cr-Mo-C alloy produced by rapid solidification will increase by increasing the cooling rate. Increasing the cooling rate from $10 \mathrm{~K} / \mathrm{s}$ to $450 \mathrm{~K} / \mathrm{s}$ will raise the corrosion potential from $-280 \mathrm{~V}$ to $-240 \mathrm{~V}$ and reduce the corrosion rate from $0.09 \mu \mathrm{A} / \mathrm{cm}^{2}$ to 0.02 $\mu \mathrm{A} / \mathrm{cm}^{2}$.

\section{References}

[1] Hiromoto S, Onodera E, Chiba A, Asami K, Hanawa T. Microstructure and corrosion behaviour in biological environments of the new forged low-Ni Co-Cr-Mo alloys. Biomaterials. 2005;26(24):4912-4923.

[2] Munoz AI, Schwiesau J, Jolles BM, Mischler ST. In vivo electrochemical corrosion study of a CoCrMo biomedical alloy in human synovial fluids. Acta Biomaterialia. 2015;21:228-236.

[3] Ramirez-Ledesma A, Lopez H, Juarez-Islas J. Evaluation of chill cast Co-Cr Alloys for biomedical applications. Metals. 2016;6(8):188.

[4] Brooks CR. Heat treatment, structure, and properties of nonferrous alloys. Ohio American Society for Metals: inMetals park; 1982. 
[5] Julian LC, Munoz AI. Influence of microstructure of HC CoCrMo biomedical alloys on the corrosion and wear behaviour in simulated body fluids. Tribology International. 2011;44(3):318-329.

[6] Lopez HF, Saldivar-Garcia AJ. Martensitic transformation in a cast Co-Cr-Mo-C alloy. Metallurgical and Materials Transactions A. 2008;39(1):8-18.

[7] Hsu RW, Yang CC, Huang CA, Chen YS. Electrochemical corrosion studies on Co-Cr-Mo implant alloy in biological solutions. Materials Chemistry and Physics. 2005;93(2-3):531-538.

[8] Kaiser R, Williamson K, O’Brien C, Browne DJ. Effects of section size, surface cooling conditions, and crucible material on microstructure and as-cast properties of investment cast Co-Cr biomedical alloy. Metallurgical and Materials Transactions A. 2013;44(12):5333-5342.

[9] Lee SH, Takahashi E, Nomura N, Chiba A. Effect of heat treatment on microstructure and mechanical properties of $\mathrm{Ni}$-and $\mathrm{C}$-free $\mathrm{Co}-\mathrm{Cr}-\mathrm{Mo}$ alloys for medical applications. Materials Transactions. 2005;46(8):1790-1793.

[10] ASTM F75-12. Standard specification for cobalt-28 chromium-6 molybdenum alloy castings and casting alloy for surgical implants (UNS R30075). West Conshohocken, PA: ASTM International; 2012.

[11] Gupta KP. The Co-Cr-Ta (Cobalt-Chromium-Tantalum) System. Journal of Phase Equilibria and Diffusion. 2005;26:93-97.

[12] Li Y, Wang J, Zhu X, Feng Q, Li X, Feng X. Urinary protein markers predict the severity of renal histological lesions in children with mesangial proliferative glomerulonephritis. BMC Nephrology. 2012;13(1):29.

[13] Koerten HK, Onderwater JJ, Koerten EW, Bernoski FP, Nelissen RG. Observations at the articular surface of hip prostheses: an analytical electron microscopy study on wear and corrosion. Journal of Biomedical Materials Research. 2001;54:591-596.

[14] Puleo DA. Biochemical surface modification of Co-Cr-Mo. Biomaterials. 1996;17(2):217-222.

[15] Mori M, Yamanaka K, Sato S, Wagatsuma K, Chiba A. Microstructures and mechanical properties of biomedical Co-29Cr-6Mo-0.14N alloys processed by hot rolling. Metallurgical and Materials Transactions A. 2012;43(9):3108-3119.

[16] Ramirez-Ledesma AL, Lopez-Molina E, Lopez HF, Juarez-Islas JA. Athermal $\varepsilon$-martensite transformation in a Co-20Cr alloy: Effect of rapid solidification on plate nucleation. Acta Materialia. 2016;111:138-147.

[17] Olson GB, Cohen M. A general mechanism of martensitic nucleation: Part I. General concepts and the FCC $\rightarrow$ HCP transformation. Metallurgical Transactions A. 1976;7(12):1897-1904.

[18] Nakayama H. Dentistry and metal allergy. London: Dental-Diamond Co; 1997.

[19] Petrov YN, Prokopenko GI, Mordyuk BN, Vasylyev MA, Voloshko SM, Skorodzievski VS, Filatova VS. Influence of microstructural modifications induced by ultrasonic impact treatment on hardening and corrosion behavior of wrought Co-Cr-Mo biomedical alloy. Materials Science and Engineering: C. 2016;58:1024-1035.

[20] Ren F, Zhu W, Chu K. Fabrication, tribological and corrosion behaviors of ultra-fine grained Co-28Cr-6Mo alloy for biomedical applications. Journal of the Mechanical Behavior of Biomedical Materials. 2016;60:139147.

[21] Rodrigues WC, Broilo LR, Schaeffer L, Knörnschild G, Espinoza FR. Powder metallurgical processing of Co-28\%Cr-6\%Mo for dental implants: Physical, mechanical and electrochemical properties. Powder Technology. 2011;206(3):233-238.

[22] Kordijazi A. Electrochemical characteristics of an optimized Ni-P-Zn electroless composite coating. Advanced Materials Research. 2014;1043:124-128.

[23] Zarandi MA, Pillai KM, Kimmel AS. Spontaneous imbibition of liquids in glass - fiber wicks. Part I: Usefulness of a sharp - front approach. AIChE Journal. 2018;64(1):294-305.

[24] Erfanian-Naziftoosi HR, López HF. The effect of rapid solidification on microstructure and mechanical properties of advanced biomaterial Co-Cr-Mo-C alloy. International Journal of Advances in Science, Engineering and Technology. 2019;7:17-19.

[25] Taylor RN, Waterhouse RB. A study of the ageing behaviour of a cobalt based implant alloy. Journal of Materials Science. 1983;18(11):3265-3280.

[26] Sage M, Guillaud C. Method for the quantitative analysis of allotropic varieties of cobalt by X-rays. Revue de metallurgie. 1950;47(2):139-145. (in French).

[27] Hirth JP. Thermodynamics of stacking faults. Metallurgical Transactions. 1970;1(9):2367-2374.

[28] Stack MM, Rodling J, Mathew MT, Jawan H, Huang W, Park G, Hodge C. Micro-abrasion-corrosion of a Co-Cr/UHMWPE couple in Ringer's solution: An approach to construction of mechanism and synergism maps for application to bio-implants. Wear. 2010;269(5-6):376-382.

[29] Antony KC. Wear-resistant cobalt-base alloys. JOM. 1983;35(2):52-60.

[30] Zhuang LZ, Langer EW. Effects of cooling rate control during the solidification process on the microstructure and mechanical properties of cast Co-Cr-Mo alloy used for surgical implants. Journal of Materials Science. 1989;24(2):381-388. 
[31] Escobedo J, Méndez J, Cortés D, Gómez J, Méndez M, Mancha H. Effect of nitrogen on the microstructure and mechanical properties of a Co Cr Mo alloy. Materials \& Design. 1996;17(2):79-83.

[32] Bonagani SK, Bathula V, Kain V. Influence of tempering treatment on microstructure and pitting corrosion of 13 wt.\% Cr martensitic stainless steel. Corrosion Science. 2018;131:340-354.

(C) 2019 by the author(s). This work is licensed under a Creative Commons Attribution 4.0 International License (http://creativecommons.org/licenses/by/4.0/). Authors retain copyright of their work, with first publication rights granted to Tech Reviews Ltd. 